\title{
Active video games: the mediating effect of aerobic fitness on body composition
}

\author{
Ralph Maddison ${ }^{1,4^{*}}$, Cliona Ni Mhurchu1, Andrew Jull ${ }^{2}$, Harry Prapavessis ${ }^{3}$, Louise S Foley ${ }^{1}$ and Yannan Jiang ${ }^{1}$
}

\begin{abstract}
Background: Increased understanding of why and how physical activity impacts on health outcomes is needed to increase the effectiveness of physical activity interventions. A recent randomized controlled trial of an active video game (PlayStation EyeToy ${ }^{\text {TIM }}$ ) intervention showed a statistically significant treatment effect on the primary outcome, change from baseline in body mass index (BMI), which favored the intervention group at 24 weeks. In this short paper we evaluate the mediating effects of the secondary outcomes.

Objective: To identify mediators of the effect of an active video games intervention on body composition.

Methods: Data from a two-arm parallel randomized controlled trial of an active video game intervention $(n=322)$ were analyzed. The primary outcome was change from baseline in BMI. A priori secondary outcomes were considered as potential mediators of the intervention on BMI, including aerobic fitness $\left(\mathrm{VO}_{2 \mathrm{Max}}\right)$, time spent in moderate-to-vigorous physical activity (MVPA), and food snacking at 24 weeks.

Results: Only aerobic fitness at 24 weeks met the conditions for mediation, and was a significant mediator of BMI. Conclusion: Playing active video games can have a positive effect on body composition in overweight or obese children and this effect is most likely mediated through improved aerobic fitness. Future trials should examine other potential mediators related to this type of intervention.
\end{abstract}

Trial registration: Australian New Zealand Clinical Trials Registry

Website: http://www.anzctr.org.au

Study ID number: ACTRN12607000632493

Keywords: Active video games, Physical activity, Sedentary behavior, Children, Overweight

\section{Findings}

\section{Introduction}

Increased understanding of why and how physical activity impacts on health outcomes is needed to increase the effectiveness of physical activity interventions. A recent randomized controlled trial of an active video game (PlayStation EyeToy ) intervention showed a statistically significant treatment effect on the primary outcome, change from baseline in body mass index (BMI), which favored the intervention group at 24 weeks [1]. Active video games are electronic games that allow players to physically interact (using arm, leg, or whole-body movement) with

\footnotetext{
* Correspondence: r.maddison@ctru.auckland.ac.nz

${ }^{1}$ Clinical Trials Research Unit, University of Auckland, Auckland, New Zealand

${ }^{4}$ Clinical Trials Research Unit, University of Auckland, Private Bag 92019,

Auckland, 1142, New Zealand

Full list of author information is available at the end of the article
}

images onscreen in a variety of activities such as sports (e.g., football, boxing, martial arts) and other activities (e.g., dancing, washing windows).

In this short paper we evaluate the mediating effects of the secondary outcomes. Treatment mediators identify possible mechanisms through which a treatment might achieve its effects. These mechanisms are causal links between treatment and outcome [2].

\section{Methods}

A two-arm parallel randomized controlled trial was conducted in Auckland, New Zealand from February 2008 to January 2010. 322 overweight and obese children aged 10-14 years, who were current users of sedentary video games were randomly assigned to either receive an active video game intervention $(n=160)$ or no change (control group; $\mathrm{n}=162$ ). Full details of recruitment, 
participant flow through the study and measures have been published elsewhere [1,3].

In brief, participants were recruited through schools and various community locations in Auckland city. Eligible participants were aged 10-14 years, overweight or obese (according to the International Obesity Task Force international cut-offs for child obesity) [4], and owned a PlayStation ${ }^{\circledR} 2$ or 3 gaming console, but no active video games, including EyeToy ${ }^{\text {wa }}$ or Nintendo Wii; and played $\geq$ two hours of video games per week. Participants were excluded if they had contraindications to performing physical activity (such as a medical condition). One child per household was eligible to take part. Dropout from the study was $24 \%$ and $17 \%$ for the intervention and control groups, respectively.

Intervention participants received an upgrade (hardware and games) of existing gaming technology enabling them to play Sony PlayStation EyeToy" active video games at home. A selection of active video games (e.g., Play3, Kinetic, Sport, and Dance Factory; Sony) were provided on the basis of being current releases and offering a variety of activity options. Published MET (Metabolic Equivalent) values for these types of games range from 2.0-5.0 [5,6]. Children were encouraged to meet current physical activity recommendations (60 minutes of moderate to vigorous physical activity on most days of the week) [7] by supplementing periods of inactivity with active video game play and substituting periods of traditional non-active video game play with the active version. To ensure the sustainability of the intervention [8] children were sent a package of new active video games at 12 weeks. Active video game play was sustained at higher levels than baseline at both 12 and 24 weeks in intervention participants [1], suggesting this strategy was successful. The control group continued with their normal video game play. On completion of the study, participants in the control group received the active video games upgrade package at no cost.

\section{Measures}

All outcomes were measured at baseline 12 and 24 weeks. Anthropometric data (height and weight) were measured using standard practices [9]. Body fat was assessed using standardized bio-electrical impedance analysis procedures [10] with the ImpediMed DF50 Bioimpedence Monitor (Queensland, Australia). This method has been validated against deuterium dilution and specific prediction equations developed in New Zealand children [11]. Aerobic fitness was assessed using the 20 meter shuttle test $[12,13]$. Seven day physical activity was measured objectively using accelerometry [14], and daily (for seven days) self-reported snack food consumption was assessed using a participant diary developed and tested in a previous pilot study [8].

The primary outcome was change from baseline in BMI, while percentage body fat was measured as a secondary outcome. A priori secondary outcomes were considered as potential mediators of the intervention effect on BMI and percentage body fat, including aerobic fitness $\left(\mathrm{VO}_{2 \mathrm{Max}}\right)$, time spent in moderate-to-vigorous physical activity (MVPA), and food snacking at 24 weeks.

In accordance with the recommendations of Kraemer et al [2] for testing mediators of treatment effects in randomized clinical trials, hierarchical regression analyses were conducted on the observed participants' data with change from baseline to 24 weeks in BMI and percentage body fat as the criterion measures. According to Kraemer and colleagues, a mediator must measure an event or change occurring during treatment, and then it must correlate with treatment choice, hence possibly be a result of treatment, and have either a main or interactive effect on the outcome. Their analytic approach differs conceptually from that of Baron and Kenny [15] in several important ways. According to Kraemer et al. with mediation, demonstration of precedence is required. A mediator occurs during treatment. Similarly, demonstration of correlation is required. They argue that in absence of such criteria, the interpretation of

Table 1 Treatment effects with mediator variable $\mathrm{VO}_{2 \mathrm{Max}}$

\begin{tabular}{|c|c|c|c|c|c|c|c|c|c|}
\hline \multirow[b]{3}{*}{$\begin{array}{l}\text { Change from } \\
\text { baseline }\end{array}$} & \multicolumn{4}{|c|}{ Treatment effect } & \multicolumn{4}{|c|}{ Difference in treatment effect } & \multirow{3}{*}{$\begin{array}{c}\text { Overall mediation } \\
\text { p }\end{array}$} \\
\hline & \multicolumn{2}{|c|}{ Intervention } & \multicolumn{2}{|c|}{ Control } & \multirow[b]{2}{*}{$\begin{array}{l}\text { Difference } \\
\text { in means }\end{array}$} & \multirow[b]{2}{*}{ SE } & \multirow[b]{2}{*}{ Lower 95\% C.I. } & \multirow[b]{2}{*}{ Upper 95\% C.I. } & \\
\hline & Mean & SE & Mean & SE & & & & & \\
\hline \multicolumn{10}{|l|}{$\mathrm{BMI}\left(\mathrm{kg} / \mathrm{m}^{2}\right)$} \\
\hline Main* & 0.11 & 0.11 & 0.44 & 0.11 & -0.33 & 0.12 & -0.57 & -0.08 & \\
\hline $\mathrm{VO}_{2 \mathrm{Max}} \#$ & 0.13 & 0.11 & 0.43 & 0.11 & -0.30 & 0.13 & -0.56 & -0.04 & $<.0001$ \\
\hline \multicolumn{10}{|l|}{$\begin{array}{l}\text { Percentage \% } \\
\text { Body Fat }\end{array}$} \\
\hline Main* & -0.99 & 0.29 & -0.16 & 0.30 & -0.83 & 0.36 & -1.54 & -0.12 & \\
\hline $\mathrm{VO}_{2 \mathrm{Max}} \#$ & -0.93 & 0.32 & -0.52 & 0.33 & -0.41 & 0.39 & -1.19 & 0.36 & $<.0001$ \\
\hline
\end{tabular}

Note: * Main effect without mediator.

\# Mediator at post-intervention (24 weeks). 
whether a relationship is mediating or moderating is often arbitrary. The analytic model, in contrast to the several linear model proposed by Baron and Kenny, is exactly the same for moderators and mediators. The difference lies in how M (Mediator or Moderator) is defined in terms of time relation to treatment onset and correlation with treatment choice [2].

\section{Results}

All statistical analyses were performed using SAS version 9.1.3 (SAS Institute Inc. Cary NC) and R [16] version 2.10.0. Statistical tests were two-tailed and a 5\% significance level maintained throughout the analyses. Only aerobic fitness at 24 weeks met the conditions for mediation, and was a significant mediator of all treatment outcomes $(p<0.0001)$ evaluated in the above models. The level of mediation differed for each response (Table 1). For change in BMI, the observed difference between the two treatment groups reduced from $-0.3265(p=0.01)$ to -0.2992 $(p=0.02)$, or approximately $8 \%$ when aerobic fitness was included. For percentage body fat, the observed group difference shifted from $-0.291 \quad(p=0.02)$ to -0.4136 $(p=0.03)$, or approximately $50 \%$. No statistically significant mediating effects were found for any of the other variables of interest.

\section{Conclusion}

Playing active video games can have a positive effect on body composition in overweight or obese children and this effect is most likely mediated through improved aerobic fitness. Consistent with previous research [17] we found no effect of the intervention on measured physical activity. The lack of effect on measured physical activity might be in part explained by the large variability of physical activity within individuals and low measurement precision of accelerometers to capture non-ambulatory activity. Here aerobic fitness may have served as a proxy measure of increased physical activity. Future trials should examine other potential mediators related to this type of intervention. Such mediators might include attitudes to or preferences for physical activity, or changes in sedentary behaviour. Our study adopted a very pragmatic approach to video game play by allowing the participants as little or as much as they wished; however future studies may find greater utility in prescribing time spent in active gaming for greater effects on aerobic fitness.

\section{Abbreviations}

BMl: Body mass index; MVPA: Moderate-to-vigorous physical activity; $\mathrm{VO}_{2 \mathrm{Max}}$ : Maximal oxygen consumption

\section{Competing interests}

Sony Computer Entertainment Europe provided the gaming software for the study. The funders and Sony Computer Entertainment Europe played no role in the design, conduct or analysis of the study, nor in the interpretation and reporting of the study findings. The authors declare they have no conflicts of interest.

\section{Acknowledgements}

This was an investigator-initiated study funded by a grant from the Health Research Council of New Zealand (07/077B). RM was supported by a Heart Foundation of New Zealand Fellowship. LF was supported by a Tertiary Education Commission Bright Futures Doctoral Scholarship. CNM is supported by the Heart Foundation of New Zealand Senior Fellowship (Grant 1380).

The authors would like to acknowledge the contributing co-investigators, Professor Anthony Rodgers, Ph.D, The George Institute for International Health, Sydney, New South Wales, Australia, Dr Maea Hohepa, Sport and Recreation New Zealand.

\section{Author details}

${ }^{1}$ Clinical Trials Research Unit, University of Auckland, Auckland, New Zealand. ${ }^{2}$ School of Nursing, University of Auckland, Auckland, New Zealand. ${ }^{3}$ School of Kinesiology, Faculty of Medical and Health Sciences, University of Western Ontario, London, ON, Canada.

\section{Authors' contributions}

RM provided study oversight. LF conducted the research and undertook data collection. YJ performed the statistical analyses. RM, CNM, AJ, AR all designed the research (project conception and development of overall research plan). $\mathrm{RM}$ wrote the paper. All authors assisted in interpretation of the analyses and revising the paper. All authors read and approved the final manuscript. RM takes primary responsibility for final content. RM has had full access to all of the data in the study and takes responsibility for the integrity of the data and the accuracy of the data analysis. All authors read and approved the final manuscript.

Received: 13 December 2011 Accepted: 3 May 2012

Published: 3 May 2012

\section{References}

1. Maddison R, Foley L, Ni Mhurchu C, et al: Effects of active video games on body composition: a randomized controlled trial. Am J Clin Nutr 2011, 94. doi:10.3945/ajen.3110.009142.

2. Kraemer H, Wilson GT, Fairburn CG, Agras WS: Mediators and moderators of treatment effects in randomized clinical trials. Arch General Psych 2002, 59:877-883.

3. Maddison R, Foley L, Ni Mhurchu C, et al: Active video games to improve body composition and increase physical activity in overweight children: design and conduct of the Electronic Games to Aid Motivation to Exercise (eGAME) randomised controlled trial. BMC Publ Health 2009, 9 (1):146.

4. Cole TJ, Bellizzi MC, Flegal KM, Dietz WH: Establishing a standard definition for child overweight and obesity worldwide: international survey. BMJ 2000, 320:1240-1243.

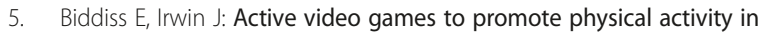
children and youth. Arch Ped Adolesc Med 2010, 164(7):664-672.

6. Maddison R, Ni Mhurchu C, Jull A, Jiang Y, Prapavessis H, Rodgers A: Energy expended playing video console games: an opportunity to increase children's physical activity? Ped Exerc Sci 2007, 19(3):334-343.

7. Sport and Recreation New Zealand. Activity Guidelines (5-18 year olds): 2009. http://www.sparc.org.nz/getting-active/activity-guidelines.

8. Ni Mhurchu C, Maddison R, Jiang $Y$, Jull A, Prapavessis $H$, Rodgers A: From couch potatoes to jumping beans: a pilot study of the effect of active video games on physical activity in children. Int J Behav Nutr Phys Act 2008, 5(8). doi:10.1186/1479-5868-1185-1188.

9. McArdle WD, Katch FI, Katch VL: Exercise Physiology: Energy, Nutrition, and Human Performance. Philadelphia: Lea and Febiger; 1991.

10. Lukaski HC, Bolonchuk WW, Hall CB, Siders WA: Validation of tetrapolar bioelectrical impedance method to assess human body composition. $J$ Appl Physiol 1986, 60(4):1327-1332.

11. Rush E, Puniani K, Valencia M, Davies P, Plank L: Estimation of body fatness from body mass index and bioelectrical impedance: comparison of New Zealand European, Maori and Pacific Island children. Eur J Clin Nutr 2003, 57:1394-1401 
12. Tomkinson G, Léger L, Olds T, Cazorla G: Secular trends in the performance of children and adolescents (1980-2000): an analysis of 55 studies of the $20 \mathrm{~m}$ shuttle run in 11 countries. Sports Med 2003, 33:285-300.

13. Ramsbottom R, Brewer J, Williams C: A progressive shuttle run test to estimate maximal oxygen uptake. British J Sports Med 1988, 22:141-144.

14. Freedson P, Pober D, Janz KF: Calibration of accelerometer output for children. Med Sci Sports Exerc 2005, 37(11):S523-S530.

15. Baron RM, Kenny DA: The moderator-mediator variable distinction in social psychological reserach: conceptual, strategic and statistical considerations. J Pers Soc Psych 1986, 51:1173-1182.

16. R-collaboration; http://www.r-project.org/.

17. Puder J, Marques-Vidal P, Schindler C, et al: Effect of multidimensional lifestyle intervention on fitness and adiposity in predominantly migrant preschool children (Ballabeina): cluster randomised controlled trial. BMJ 2011, 343:d6195

doi:10.1186/1479-5868-9-54

Cite this article as: Maddison et al: Active video games: the mediating effect of aerobic fitness on body composition. International Journal of Behavioral Nutrition and Physical Activity 2012 9:54.

\section{Submit your next manuscript to BioMed Central and take full advantage of:}

- Convenient online submission

- Thorough peer review

- No space constraints or color figure charges

- Immediate publication on acceptance

- Inclusion in PubMed, CAS, Scopus and Google Scholar

- Research which is freely available for redistribution 